\title{
SNA and SNB Angles in a Population of Nubian Schoolchildren
}

\author{
SUSAN J. WALKER, JAMES E. HARRIS, and CHARLES J. KOWALSKI \\ Department of Orthodontics and Dental Research Institute, Lniversity of Michigan, \\ Ann Arbor, Michigan 48104, USA
}

The descriptive statistics for the sella-nasion. $A$ point ( $S N A$ ) and sella-nasion-B point (SNB) angles computed from a sample of Nubian schoolchildren are presented, by age and sex, and compared with the analogous statistics for American Caucasian schoolchildren.

The importance of the sella-nasion-A point (SNA) and sella-nasion-B point (SNB) angles in clinical cephalometry has long been recognized, and much attention has been focused on deriving normal values for these measurements which would be applicable in the treatment of the average American child of average age. In a number of separate studies, various investigators have incorporated these angles into their batteries of diagnostic variables in an attempt to describe the craniofacial morphology of selected groups of individuals and to quantify the concepts of upper (SNA) and lower (SNB) facial prognathism for use in orthodontic diagnosis, case assessment, and treatment planning. To cite a few examples, Steiner ${ }^{1,2}$ studied the distributions of the SNA and SNB angles in a group of patients undergoing orthodontic treatment to determine the relative position of the maxilla to the mandible or, less formally, to answer the question of whether the chin is forward or backward in relation to those structures that would affect the individual's facial appearance and the impression he would make on the people about him. Downs ${ }^{3.4}$ studied these variables in 20 persons, ten males and ten females, with clinically excellent occlusions who were from 12 to 17 years old. $\mathrm{He}$ also used the facial plane and the A-B plane as meaures of the degree of recession

This work was supported in part by NiH Grant No. 03-011-1.

Received for publication July 25, 1974.

Accepted for publication November 8, 1974. or protrusion of the lower jaw. Walker and Kowalski ${ }^{5} .6$ studied 2,500 Caucasian elemen. tary and secondary schoolchildren with normal occlusions. They $\bar{i}, 8$ also derived age and sex-specific norms for normal males and females from 6 to 26 years of age and contrasted the distributions of these angles in this population with those found by Downs and Steiner.

All of these studies, however, concentrated on the establishment of normative values for selected groups of American Caucasian children. The purpose of this paper is to present the descriptive statistics for a different racial group-Nubian schoolchildren from Ballana, Egypt-and to compare the SNA and $S N B$ angles of this group with the norms for American Caucasian schoolchildren in the same age range.

\section{Materials and Methods}

The present study is based on protractor measurements obtained from cephalometric tracings of lateral radiographs of 149 male and 105 female Nubian schoolchildren who were 6 to 18 years old; the measurements were collected as part of our study of the craniofacial morphology of ancient and modern Nubians. 9 This sample is expected to be representative of normal variation in the Nubian population inasmuch as no special criteria, except the availability of the individual, were used in selecting the subjects. Radiographs were taken using the standard Wehmer headholder and a $90 \mathrm{kv}$ $\mathrm{X}$-ray source powered by a 3,000-w portable generator ${ }^{10}$; these were developed in a darkroom by a standard wet-process technique. All the statistical analyses were performed using MIDAS (Michigan Interactive Data Analysis System) developed by the Statistical Research Laboratory of the University of Michigan. 


\section{TABLE 1}

Descriptive Statistics for the SNA ANgle in 149 Male and

105 Female Nubian Schoolchildren from 6 to 18 Years of Age

\begin{tabular}{|c|c|c|c|c|c|c|c|c|c|c|}
\hline \multirow[b]{2}{*}{ Age } & \multicolumn{5}{|c|}{ Male } & \multicolumn{5}{|c|}{ Female } \\
\hline & $\mathbf{N}$ & Mean & $S D^{*}$ & Minimum & Maximum & $\mathrm{N}$ & Mean & $S D$ & Minimum & Maximum \\
\hline $6-7$ & 22 & 81.68 & 2.90 & 74.0 & 86.0 & 22 & 81.36 & 4.15 & 70.5 & 88.0 \\
\hline $8-9$ & 21 & 80.48 & 2.91 & 76.0 & 87.0 & 8 & 83.50 & 4.42 & 75.5 & 89.0 \\
\hline 10.11 & 33 & 81.53 & 2.77 & 75.0 & 86.0 & 18 & 81.11 & 3.97 & 73.5 & 88.0 \\
\hline $12-13$ & 23 & 79.48 & 4.27 & 72.0 & 86.5 & 18 & 81.67 & 2.30 & 77.0 & 85.5 \\
\hline $14-15$ & 36 & 81.27 & 3.31 & 75.5 & 91.5 & 21 & 81.81 & 3.59 & 74.0 & 88.5 \\
\hline $16-17$ & 14 & 82.18 & 4.10 & 77.5 & 92.5 & 8 & 82.06 & 2.20 & 76.5 & 84.5 \\
\hline
\end{tabular}

* $S D$, standard deviation.

TABLE 2

Descriptive Statistics for the SNB Angle in 149 Male and

105 Female Nubian Schoolchildren From 6 to 18 Years of AgE

\begin{tabular}{|c|c|c|c|c|c|c|c|c|c|c|}
\hline \multirow[b]{2}{*}{ Age } & \multicolumn{5}{|c|}{ Male } & \multicolumn{5}{|c|}{ Female } \\
\hline & $\mathrm{N}$ & Mean & $S D^{*}$ & Minimum & Maximum & $N$ & Mean & $S D$ & Minimum & Maximum \\
\hline $6-7$ & 22 & 77.02 & 3.03 & 70.0 & 82.5 & 22 & 76.91 & 4.13 & 68.0 & 82.5 \\
\hline 8.9 & 21 & 77.29 & 2.35 & 72.5 & 81.0 & 8 & 78.75 & 2.34 & 76.0 & 82.0 \\
\hline $10-11$ & 33 & 77.29 & 3.02 & 71.0 & 83.0 & 18 & 77.67 & 3.62 & 72.0 & 83.5 \\
\hline $12 \cdot 13$ & 23 & 76.24 & 3.72 & 67.5 & 82.5 & 18 & 78.03 & 2.53 & 73.0 & 84.0 \\
\hline $14-15$ & 36 & 78.11 & 2.42 & 72.0 & 84.5 & 21 & 78.71 & 3.35 & 71.5 & 85.5 \\
\hline $16-17$ & 14 & 79.54 & 4.78 & 70.5 & 89.0 & 18 & 78.42 & 2.90 & 74.5 & 87.5 \\
\hline
\end{tabular}

* $S D$, standard deviation.

\section{Results}

Table I contains the descriptive statistics (sample size, mean, standard deviation, minimum and maximum values) of the SNA angle, by age and sex, in the Nubian sample, and Table 2 contains the corresponding information for the SNB angle. In Table 3 we give the age- and sex-specific mean values for the ANB angle (computed as the difference of the mean SNA and SNB angle values) in the Nubian sample and the corresponding values for the ANB angle for American

TABLE 3

Mean Values of the ANB Angle for Male and Female Nubian and CaUCasian ${ }^{\circ}$ Schoolchildren FROM 6 TO 18 YEARS OF AGE

\begin{tabular}{|c|c|c|c|c|}
\hline \multirow[b]{2}{*}{ Age } & \multicolumn{2}{|c|}{ Nubian } & \multicolumn{2}{|c|}{ Caucasian } \\
\hline & Male & Female & Male & Female \\
\hline $6-7$ & 4.66 & 4.45 & 5.18 & 4.24 \\
\hline $8-9$ & 2.19 & 4.75 & 5.16 & 4.22 \\
\hline $10-11$ & 4.24 & 3.44 & 5.09 & 4.61 \\
\hline $12-13$ & 3.24 & 3.64 & 4.93 & 4.21 \\
\hline $14-15$ & 3.16 & 3.10 & 4.22 & 4.24 \\
\hline $16-17$ & 2.74 & 3.64 & 3.88 & 4.46 \\
\hline
\end{tabular}

Caucasian children as reported by Walker and Kowalski. ${ }^{6}$

\section{Discussion}

According to Table 1, which shows the distribution of the SNA angle, there is no evidence of sexual dimorphism and no consistent developmental pattern. This suggests that we may pool the sample by age and sex to obtain an overall mean value of the order of $81^{\circ}$, which is the same as Down's mean value but is somewhat lower than Steiner's suggested ideal value of $82^{\circ}$. Comparison with the Walker-Kowalski norms, ${ }^{5}$ which were computed for the same age groups as the Nubian sample, shows a slight, but consistent, tendency for the SNA angle to be smaller among the Nubian schoolchildren than in the Caucasian sample.

The SNB angle is somewhat larger in the Nubian sample than that reported by Walker and Kowalski ${ }^{5}$ and, especially among the males, this angle tends to increase with increasing age. This tendency also was noted by Walker and Kowalski ${ }^{5-8}$ in their sample of American Caucasian schoolchildren, but it was not considered by either Downs or 
Steiner who provided norms that did not take age or sex into account. The overall mean value for the SNB angle is compatible with Down's mean value of $78^{\circ}$, but is some what lower than Steiner's suggested ideal value of $80^{\circ}$.

Table 3 shows that the mean values of the ANB angle become progressively more acute with age in both the Nubian and Caucasian samples. Male and female Nubians have smaller ANB angles than their Caucasian counterparts. These mean values, however, are still considerably higher than Steiner's suggested ideal value of $2^{\circ}$ for this measurement. The closure of the ANB angle with age is more pronounced among the males of both groups and, if the Nubian growth pattern follows that of American Caucasian males where mandibular growth continues into the early to mid. $20 \mathrm{~s}, 8$ this sexual dimorphism is expected to become even more pronounced.

\section{Conclusions}

Nubian children have smaller SNA angles, larger SNB angles, and smaller ANB angles than American Caucasian children of the same age groups. Within the Nubian sample, the males show a stronger tendency for the $S N^{\top} B$ angle to increase with age and this, as is the case among Caucasian males, may be related to a somewhat longer growth period for the mandibular structures among males.

\section{References}

1. Steiner, C.C.: Cephalometrics in Clinical Practice, Angle Orthod 29: 8-29, 1959.

2. Steiner, C.C.: Cephalometrics for You and Me, Am J Orthod 39: 729-755, 1953.

3. Downs, W.B.: Variations in Facial Relationships: Their Significance in Treatment and Prognosis, Am J Orthod 34: 812-840, 1948.

4. Downs, W.B.: The Role of Cephalometrics in Orthodontic Case Analysis and Diagnosis, Am J Orthod 38: 162-182, 1952.

5. Walker, G.F., and Kowalski, C.J.: On the Use of the SNA and SNB Angles in Cephalometric Analyses, Am J Orthod 64:517-523, 1973.

6. Walker, G.F., and Kowalski, C.J.: The Distribution of the AN'B Angle in "Normal" Individuals, Angle Orthod 41: 332-335, 1971.

7. WALker, G.F., and Kowalski, C.J.: Use of Angular Measurements of Cephalometric Analyses, J Dent Res 51: 1015-1021, 1972.

8. Walker, G.F., and Kowalski, C.J.: On the Growth of the Mandible, Am J Phys Anthropol 36: 111-117, 1972.

9. Harris, J.E.; Ponitz, P.Y.; and Loutyy, M.S.: Orthodontics' Contribution to UNESCO's Campaign To Save the Monuments of rubia: A 1970 Field Report, $\mathrm{Am}$ J Orthod 58: 578-596, 1970.

10. Harkis, J.E.; Burnor, D.R.; Loutfy, M.S.; and Ponitz, P.I.: A Field Method for the Cephalometric X-Ray Study of Skulls in Early Nubian Cemeteries, $A m J$ Phy's $A n$ thropol 24:265-273, 1966. 